Case Reports in
Gastroenterology
Case Rep Gastroenterol 2020;14:598-603

DOI: 10.1159/000509529

Published online: November 4, 2020

(C) 2020 The Author(s)

Published by S. Karger AG, Basel www.karger.com/crg

This article is licensed under the Creative Commons Attribution-NonCommercial 4.0 International License (CC BY-NC) (http://www.karger.com/Services/OpenAccessLicense). Usage and distribution for commercial purposes requires written permission.

\title{
Acute Abdomen in a 91-Year-Old Male due to Perforated Jejunal Diverticulitis
}

\author{
Francesco Sammartino Ivana Selvaggio Gioacchino Maria Montalto \\ Carolina Pasecinic Sirvjo Dhimolea Dimitri Krizzuk \\ General Surgery Department, Aurelia Hospital, Rome, Italy
}

\section{Keywords}

Jejunal diverticulitis $\cdot$ Small bowel diverticulitis $\cdot$ Small intestine

\begin{abstract}
Non-Meckel small intestine diverticular disease is a rare and mostly asymptomatic condition. However, rare cases of acute and emergent complications bear a high mortality rate. We report a case of a 91-year-old male that presented with an acute abdomen due to perforated jejunal diverticulitis. A review of the literature and key points of the condition are depicted. Although jejunal diverticulosis is rare, it must be considered in the differential diagnosis, especially in the elderly with signs of ambiguous abdominal pain and peritonitis.

(C) 2020 The Author(s)

Published by S. Karger AG, Basel

\section{Introduction}

Non-Meckel small bowel diverticular disease is rare. The duodenum is the most frequent localization with an incidence reported up to $6 \%$, followed by jejuno-ileal diverticula (JID) with an incidence under 1\% [1, 2]. JID were first described by Soemmerring in 1794 and by Sir Astley Cooper in 1807 [3, 4]. They are pseudodiverticula consisting of mucosa, submucosa, and sierosa layer, largely located on the mesenteric border, at the site of entry of the vasa recta at the locus minoris resistentiae of the bowel. The pathogenesis of this condition seems to be
\end{abstract}




\section{Case Reports in Gastroenterology}

Case Rep Gastroenterol 2020;14:598-603 DOI: $10.1159 / 000509529$

c) 2020 The Author(s). Published by S. Karger AG, Basel www.karger.com/crg

Sammartino et al.: Treatment of a Perforated Jejunal Diverticulitis

multifactorial, an association of motility disorder and increased intraluminal pressure associated with bowel wall weakness due to smooth muscle abnormalities. JID may be asymptomatic, have a chronic indolent presentation, or reveal itself during the workup of an acute abdomen. Though duodenal diverticula are more common, acute complications are more frequent in JID and may reach up to 40\% [5-7]. We present an interesting case of acute abdomen due to a perforated jejunal diverticula (JD) and a review of the literature on the subject. Written consent for the study was obtained from the patient.

\section{Case Report}

We report a case of a 91-year-old male that was admitted to our hospital for a left femur fracture. Remote surgical history showed inguinal hernia repair and appendectomy. The patient underwent a surgical reduction of the fracture with positioning of proximal intramedullary nail. On postoperative day 2 , the patient presented with postprandial abdominal pain associated with nausea and vomiting. Patient's vital signs showed a body temperature of $37.3^{\circ} \mathrm{C}$, heart rate $112 \mathrm{bpm}$, blood pressure $120 / 70 \mathrm{~mm} \mathrm{Hg}$, and a respiratory rate of 16 breaths/min. Abdominal physical examination revealed a distended abdomen, tender to palpation especially at the left side quadrants, with rebound and guarding. Blood workup analysis showed elevated white blood cells count $\left(13.00 \times 10^{9} / \mathrm{L}\right)$, C-reactive protein $17 \mathrm{mg} / \mathrm{dL}$, and a hemoglobin level of $11.8 \mathrm{~g} / \mathrm{dL}$. A CT scan of the abdomen and pelvis revealed a thickened segment of small bowel with diverticula and a pocket of free air, localized on the left side of the abdomen. Also, pneumoperitoneum and pneumatosis of the jejunum were noted, indicating a perforation.

The patient underwent an emergent exploratory laparotomy. During the procedure, turbid fluid was noted on entering the abdomen. Exploration of the jejunum revealed a tract of $100 \mathrm{~cm}$ affected by diverticula localized on the mesenteric side of the bowel. A small perforation of one of the diverticula was noted (Fig. 1-3). Systematic exploration of the abdomen revealed diverticulosis of the left colon without other significant pathology. An intestinal resection of $30 \mathrm{~cm}$ of jejunum was performed, and the intestinal continuity was restored with a termino-terminal anastomosis. No intra- or postoperative complications occurred. The patient was discharged at postoperative day 7 and was followed up at outpatient clinic. No 30day readmission was registered. Histological examination revealed perforated jejunal diverticulosis.

\section{Discussion}

JID is a rare clinical condition. Its incidence mainly depends on the used imaging diagnostics methods. On standard radiographic studies, JID is identified in $0.02-0.42 \%$ of cases. In some studies, enteroclysis was able to identify JID in up to $2.3 \%$. The reported incidence in autoptic series varies from 0.06 to $4.6 \%$ [5]. Duodenum is the most frequent site of diverticulosis (60-70\%), followed by proximal jejunum (20-25\%) and ileum (5-10\%) [8].

The manifestations of JID may range consistently. JID is asymptomatic in approximately $60-70 \%$ of patients. The remaining symptomatic population may be further divided into patients with chronic or acute manifestations. Chronic symptoms are vague and include abdominal pain, dyspepsia, weight loss, constipation, and diarrhea that may eventually lead to malabsorption and anemia. Furthermore, the vague symptoms contribute to misdiagnosis of 
Case Reports in
Gastroenterology

Case Rep Gastroenterol 2020;14:598-603

DOI: $10.1159 / 000509529$

C 2020 The Author(s). Published by S. Karger AG, Basel

www.karger.com/crg

Sammartino et al.: Treatment of a Perforated Jejunal Diverticulitis

irritable bowel syndrome, cholelithiasis, etc. $[5,9,10]$. Acute complications occur in 10-19\% of patients affected by small bowel diverticulosis and are more frequent in jejunal and ileal diverticula [9]. The reported complications of JID include hemorrhage, volvulus, diverticulitis, obstruction, abscess, and perforation and occur in $10-30 \%$ of patients $[7,11]$. The vast majority are acquired, but some solitary diverticula, found in the young, may be of congenital origin. JID are pulsion-type diverticula. The precise cause of the condition is unknown and is probably multifactorial. It may be the result of smooth-muscle abnormalities, abnormalities in peristalsis or high segmental intraluminal pressures. Intestinal dyskinesia may lead to high intraluminal pressure, which may lead to herniation of mucosa and submucosa through the weakest site of the muscolaris, which is where blood vessels penetrate the bowel wall. This explains the common location of JD at the mesenteric side of the bowel [5]. In discussing JD disease, one must also discuss enterolith formation within the diverticula. De novo stone formation is likely to commence starting from choleic acid, the end product of bile salt metabolism. Deconjugation of bile salts by bacteria in the diverticula predisposes them to precipitate and result in stone formation due to the acidic $\mathrm{pH}$ within the proximal small bowel. Another etiological basis for stone formation is stagnation of food particles due to abnormal transit with resultant debris accumulation and stone formation. These stones can then remain within the diverticula and eventually lead to various complications $[7,12]$. An association between small bowel diverticula and hereditary neuromuscular disorders such as Cronkhite-Canada syndrome has been noted, it is characterized by diffuse GI hamartomas associated with malabsorption and diarrhea. There has also been an association between jejunal diverticulosis and lipid storage diseases such as Fabry's disease, an X-linked recessive sphingolipidosis due to alpha-galactosidase deficiency [7].

Precise preoperative diagnosis of JID is challenging. The symptoms are not specific and radiologic precise diagnosis, in the urgent setting, is not straightforward. Enteroclysis seems to be the most accurate test, but it is not always available, particularly in the urgent setting. Diagnostic media, such as ultrasound, endoscopy, capsule endoscopy, deep enteroscopy with single or double balloon enteroscopy, radiotagged erythrocyte bleeding scans, and selective mesenteric arteriography, have all been used in the setting of JID. That said, CT scan is probably the gold standard imaging technique for diagnosis in the emergent setting. CT scan can allow the diagnosis based on the focal area of out-pouching of the mesenteric side of the bowel, filled or not, with feces-like material, focal asymmetric wall thickening, or inflammatory process adjacent to a loop of jejunum $[13,14]$. Finally, surgery, whether laparoscopy or laparotomy, remains the gold standard for definite diagnosis of asymptomatic and complicated diverticula $[5,15]$. Laparoscopy can be a very useful tool in diagnosing patients with puzzling signs and symptoms. It enables an accurate conclusive diagnosis to be made, avoiding the need for unnecessary laparotomy. More so, in selected cases, laparoscopic drainage, lavage, and resection with anastomosis may be performed [16].

Treatment of JID may vary based on the entity of manifestations. For an asymptomatic patient with evidence of diverticular disease of the small bowel on CT or intraoperatively, it is recommended that no action be taken. In the case of enteroliths causing obstruction, the patient should be taken to the operating room (OR) for exploration if there is no resolution of the obstruction. Once in the OR, digital or instrument fragmentation of the enterolith with milking into the distal intestine is the least invasive of operative interventions. It carries with it a success rate of $50 \%$ based on previously reported studies. If the perforated jejunal diverticulum causes only localized peritonitis and the patient remains stable, conservative treatment may be adopted. It has been reported that a conservative management with intravenous antibiotics associated with percutaneous CT-guided aspiration of localized intraperitoneal 


\section{Case Reports in Gastroenterology}

\begin{tabular}{l|l}
\hline Case Rep Gastroenterol 2020;14:598-603 \\
\hline DOI: 10.1159/000509529 & $\begin{array}{l}\text { ○ 2020 The Author(s). Published by S. Karger AG, Basel } \\
\text { www.karger.com/crg }\end{array}$ \\
\hline
\end{tabular}

Sammartino et al.: Treatment of a Perforated Jejunal Diverticulitis

collections may avoid surgery $[6,9]$. However, the current treatment of choice for perforated JD causing generalized peritonitis is prompt surgical exploration with segmental intestinal resection and primary anastomosis. The extent of the bowel resection depends upon the length of the bowel that is affected by the diverticula and the patient's perioperative condition $[6,9]$. To avoid short bowel syndrome, it is recommended to perform a limited bowel resection that includes only the segment containing the perforated diverticulum. In our case, the decision to perform a limited small bowel resection was based on the age of the patient and the good condition of the adjacent tissue which favored a safe resection and anastomosis.

In conclusion, although jejunal diverticulosis is a rare condition and the exact prevalence is unknown, its complications are not infrequent and must be considered for patients with severe peritonitis. Abdominal CT scan is an accurate, rapid and non-invasive modality to detect a small bowel perforation in the acute setting. Once jejunal diverticulosis has been diagnosed, conservative medical management should be adopted to reduce the risk of complications. In a case of perforation of JID, surgical resection of the involved intestine and primary anastomosis is the treatment of choice.

\section{Statement of Ethics}

The study was conducted according to the principles of World Medical Association Declaration of Helsinki. Written consent was collected from the patient.

\section{Conflict of Interest Statement}

None of the contributing authors have any relevant disclosures.

\section{Funding Sources}

No funding was available for this study.

\section{Author Contributions}

Francesco Sammartino prepared the initial version of the manuscript. Ivana Selvaggio, Gioacchino Maria Montalto, Carolina Pasecinic, and Sirvjo Dhimolea participated in editing and data collection. Dimitri Krizzuk revised the article and edited the final version of the manuscript.

\section{References}

1 Ejaz S, Vikram R, Stroehlein JR. Non-Meckel Small Intestine Diverticulitis. Case Rep Gastroenterol. 2017 Aug;11(2):462-472.

2 Miller RE, McCabe RE, Salomon PF, Knox WG. Surgical complications of small bowel diverticula exclusive of Meckel's. Ann Surg. 1970 Feb;171(2):202-10.

3 Soemmering S. Anatomie des krankhaften Baues von einigen der wichtigsten Theile in menschlischen Korper. Berlin: Vossiche Buchhandlung; 1794. pp 1-97.

4 Cooper A. Anatomy and Surgical Treatment of Crural Umbilical Hernia. Edinb Med Surg J. 1807;475-87. 


\section{Case Reports in Gastroenterology}

\begin{tabular}{l|l}
\hline Case Rep Gastroenterol 2020;14:598-603 \\
\hline DOI: 10.1159/000509529 & $\begin{array}{l}\text { @ 2020 The Author(s). Published by S. Karger AG, Basel } \\
\text { www.karger.com/crg }\end{array}$ \\
\hline
\end{tabular}

Sammartino et al.: Treatment of a Perforated Jejunal Diverticulitis

5 Makris K, Tsiotos GG, Stafyla V, Sakorafas GH. Small intestinal nonmeckelian diverticulosis. J Clin Gastroenterol. 2009 Mar;43(3):201-7.

6 Tsiotos GG, Farnell MB, Ilstrup DM. Nonmeckelian jejunal or ileal diverticulosis: an analysis of 112 cases. Surgery. 1994 Oct;116(4):726-31.

7 Chugay P, Choi J, Dong XD. Jejunal diverticular disease complicated by enteroliths: report of two different presentations. World J Gastrointest Surg. 2010 Jan;2(1):26-9.

8 Crace PP, Grisham A, Kerlakian G. Jejunal diverticular disease with unborn enterolith presenting as a small bowel obstruction: a case report. Am Surg. 2007 Jul;73(7):703-5.

9 Woods K, Williams E, Melvin W, Sharp K. Acquired jejunoileal diverticulosis and its complications: a review of the literature. Am Surg. 2008 Sep;74(9):849-54.

10 Balducci G, Dente M, Cosenza G, Mercantini P, Salvi PF. Multiple giant diverticula of the foregut causing upper gastrointestinal obstruction. World J Gastroenterol. 2008 May;14(20):3259-61.

11 Yaqub S, Evensen BV, Kjellevold K. Massive rectal bleeding from acquired jejunal diverticula. World J Emerg Surg. 2011 May;6(1):17.

12 Lobo DN, Braithwaite BD, Fairbrother BJ. Enterolith ileus complicating jejunal diverticulosis. J Clin Gastroenterol. 1999 Sep;29(2):192-3.

13 Coulier B, Maldague P, Bourgeois A, Broze B. Diverticulitis of the small bowel: CT diagnosis. Abdom Imaging. 2007;32(2):228-33.

14 Macari M, Faust M, Liang H, Pachter HL. CT of jejunal diverticulitis: imaging findings, differential diagnosis, and clinical management. Clin Radiol. 2007 Jan;62(1):73-7.

15 Salomonowitz E, Wittich G, Hajek P, Jantsch H, Czembirek H. Detection of intestinal diverticula by doublecontrast small bowel enema: differentiation from other intestinal diverticula. Gastrointest Radiol. 1983;8(3):271-8.

16 Spasojevic M, Naesgaard JM, Ignjatovic D. Perforated midgut diverticulitis: revisited. World J Gastroenterol. 2012 Sep;18(34):4714-20.

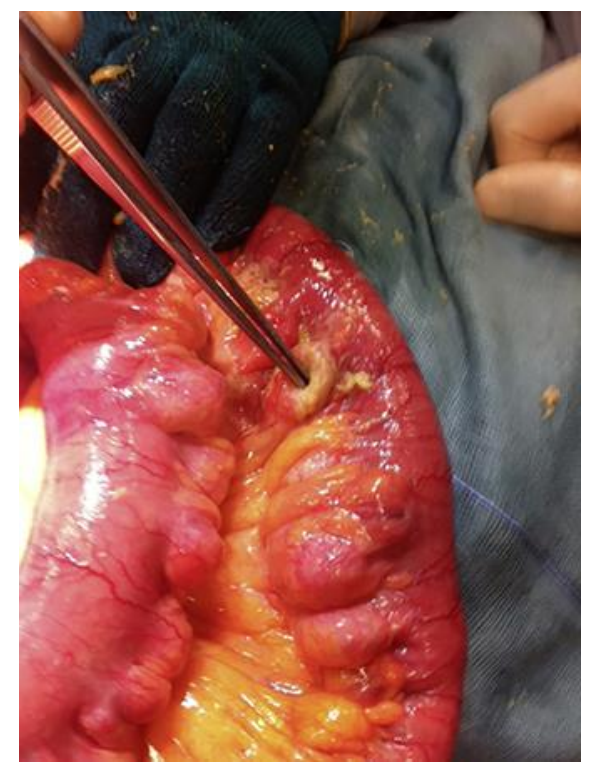

Fig. 1. Perforated jejunal diverticula (indicated with forceps edge). 
Case Reports in Gastroenterology
Case Rep Gastroenterol 2020;14:598-603

DOI: 10.1159/000509529

(c) 2020 The Author(s). Published by S. Karger AG, Basel www.karger.com/crg

Sammartino et al.: Treatment of a Perforated Jejunal Diverticulitis

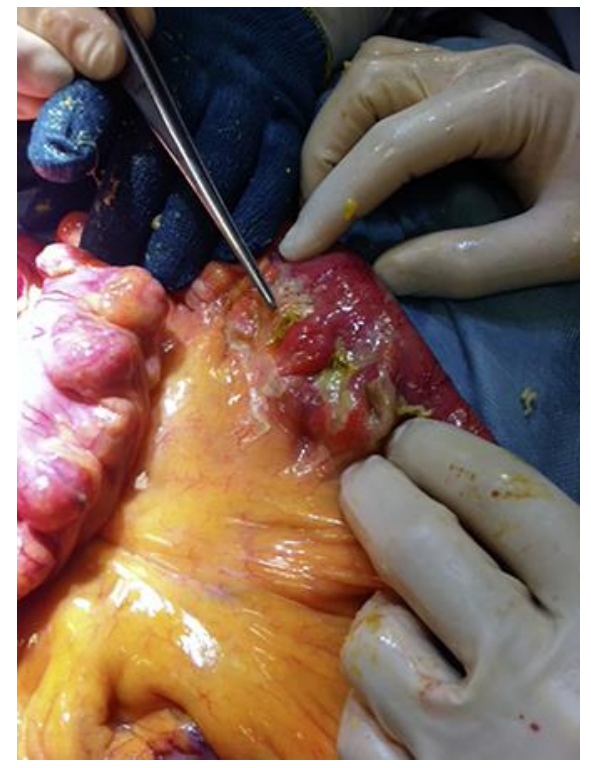

Fig. 2. Inflamed peridiverticular mesenteric tissue adjacent to the jejunal perforated diverticula.

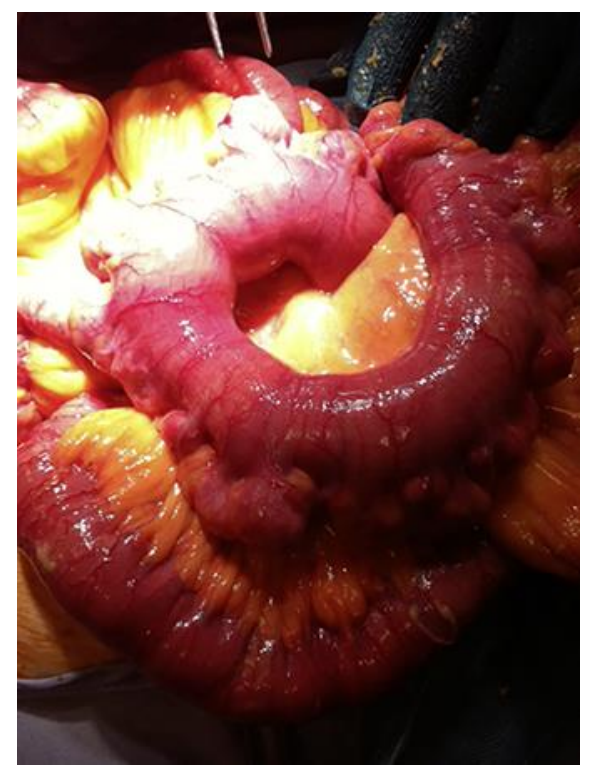

Fig. 3. Segment of the jejunum affected by diverticulosis. Diverticula typically involve the mesenteric side of the bowel as seen in the figure. 